\title{
EFEKTYWNOŚĆ INHIBITORA UREAZY NBPT W OGRANICZANIU EMISJI AMONIAKU Z MOCZNIKA I ROZTWORÓW SALETRZANO - MOCZNIKOWYCH (RSM) STOSOWANYCH W MINERALNYM ŻYWIENIU ROŚLIN
}

\begin{abstract}
Ocena skuteczności inhibitora ureazy NBPT w ograniczaniu emisji amoniaku z mocznika i RSM, nawozów powszechnie stosowanych w mineralnym żywieniu roślin uprawnych, była głównym celem badan doświadczalnych przeprowadzonych w latach 2011-2012 w kilku pomorskich gospodarstwach rolnych. W warunkach doświadczenia polowego, przeprowadzonego na trwałych użytkach zielonych, położonych na madzie średniej pylastej stwierdzono, że po zastosowaniu nawożenia azotowego pod drugi odrost traw, w dawce $60 \mathrm{~kg} \mathrm{~N} \cdot \mathrm{ha}^{-1}$, straty amoniaku po upływie 4-5 dni od aplikacji nawozów wynosiły: z mocznika -16,0\%, z mocznika stabilizowanego inhibitorem NBPT- 4,3\% w stosunku do dawki czystego składnika. Zatem można przypuszczać, że wykorzystanie do stabilizacji mocznika inhibitora ureazy NBPT spowodowało redukcję strat amoniaku o około $73 \%$. W doświadczeniach polowych przeprowadzonych na plantacjach rzepaku ozimego i pszenicy, nawożonych roztworem saletrzano - mocznikowym RSM-28, stwierdzono również, że wzbogacenie nawozu o inhibitor urazy NBPT powoduje wyraźne obniżenie emisji amoniaku. Na plantacji rzepaku ozimego, przy dawce $100 \mathrm{~kg} \mathrm{~N} \cdot \mathrm{ha}^{-1}$, dodanie inhibitora do roztworu RSM skutkowało redukcją gazowych strat azotu o ponad $50 \%$ w stosunku do strat tego składnika wykazanych w wariancie bez inhibitora. W drugim doświadczeniu przeprowadzonym na poletku z pszenicą ozimą, przy dawce $60 \mathrm{~kg} \mathrm{~N} \cdot \mathrm{ha}^{-1}$, dodanie do roztworu RSM inhibitora NBPT zmniejszyło straty amoniaku o ponad $80 \%$ w stosunku w wariantu nawożenia gdzie inhibitora nie zastosowano. We wszystkich przypadkach obniżenie emisji amoniaku miało również wpływ na zwiększenie masy plonu, co w ostatecznym rachunku zdecydowanie podnosiło nie tylko ekonomiczną ale i ekologiczną efektywność prowadzonej produkcji roślinnej.
\end{abstract}

Słowa kluczowe: mocznik, ureaza, NBPT, nawożenie, emisja amoniaku

\footnotetext{
${ }^{1}$ Autor do korespondencji/corresponding author: Tadeusz Marcinkowski, Instytut TechnologicznoPrzyrodniczy, Żuławski Ośrodek Badawczy w Elblągu, ul Giermków 5, 82-300 Elbląg, tel. 55 2324788, t.marcinkowski@itp.edu.pl

${ }^{2}$ Marek Kierończyk, Państwowa Wyższa Szkoła Zawodowa w Elblągu, ul Grunwaldzka 137, 82-300 Elbląg, m.kieronczyk@pwsz.elblag.pl
} 


\section{Wstęp}

Emisja amoniaku ze źródeł antropogenicznych w Polsce według danych Głównego Urzędu Statystycznego (GUS) w roku 2012 wynosiła 263 tys. Mg w tym z produkcji rolniczej 257 tys. Mg. Uwzględniając dwa podstawowe źródła emisji rolniczych, czyli utylizację odchodów zwierzęcych oraz uprawy polowe z zastosowaniem nawozów mineralnych, wynosiła ona odpowiednio: 176 i 81 tys. Mg. Łatwo ustalić, że ponad 31\% ulatniającego się amoniaku do atmosfery pochodzi z syntetycznych nawozów azotowych takich jak mocznik, roztwory saletrzano - mocznikowe (RSM) oraz saletra amonowa, powszechnie stosowanych w mineralnym żywieniu roślin uprawnych. Stanowi to niewątpliwie duże zagrożenie dla jakości powietrza atmosferycznego, którym oddychamy ale również jest to ogromny problem środowiskowy i ekonomiczny [4], ponieważ znaczna część azotu zastosowanego w nawozach ulatnia się bezproduktywnie do atmosfery i zasadniczo nie uczestniczy w procesie produkcyjnym. Skutkiem bezpośrednim tego procesu jest eutrofizacja naturalnych ekosystemów wodnych i lądowych, ich zakwaszanie, skutkiem pośrednim zaś wzmożona emisja gazów cieplarnianych, w tym podtlenku azotu oraz powstawanie materii zawieszonej a zwłaszcza pyłów $\mathrm{PM}_{2,5}$ i $\mathrm{PM}_{10}$ [1]. Występowanie w nawozie formy amidowej azotu (mocznik), formy amidowej i amonowej (RSM) oraz formy amonowej (saletra amonowa) z natury rzeczy sprzyja uwalnianiu się amoniaku z nawozów. W przypadku amidowej formy azotu za proces ulatniania się gazu odpowiedzialna jest hydroliza nawozu do amoniaku z udziałem enzymu ureazy, zaś w przypadku amonowej formy azotu, za ulatnianie się amoniaku odpowiadają głównie właściwości fizyko - chemiczne gleby, w tym jej kwasowość, pojemność sorpcyjna wobec kationów wymiennych, także zawartość wapnia oraz jej uwilgotnienie. Spowolnienie uwalniania się amoniaku z nawozów amidowych, przynajmniej przez okres pierwszego tygodnia po ich zastosowaniu, skutecznie można osiągnąć stosując łącznie z nawozem substancje ograniczające aktywność enzymatyczną ureazy zwane inhibitorami. Wśród wielu związków chemicznych określanych tym mianem tylko nieliczne spełniają ostre kryteria nietoksyczności w stosunku do organizmów glebowych oraz łatwo ulegają biodegradacji po upływie kilkunastu dni od ich zastosowania. Do substancji spełniających te wymagania i stosunkowo dobrze poznanych i opisanych należy między innymi triamid kwas n-butylotiofosforowego (NBPT) [7]. Jest on zarejestrowany i dopuszczony do powszechnego stosowania w wielu krajach Ameryki Północnej i wszystkich krajach UE. W Polsce po raz pierwszy skuteczność NBPT w ograniczaniu emisji amoniaku z mocznika oceniano w doświadczeniu polowym przeprowadzonym w roku 2011 na trwałych użytkach zielonych zaś z RSM-u w doświadczeniach polowych przeprowadzonych wiosną 2012 roku na plantacjach rzepaku i pszenicy ozimej. Było to głównym celem badań przeprowadzonych w kilku pomorskich gospodarstwach rolnych. Należy dodać, że w krajowej literaturze fachowej i naukowej jak dotąd brak jest odpowiednio udokumentowanych prac opisujących to zagadnienie. 


\section{Materiał i metody pomiarów}

\subsection{Doświadczenie polowe}

Pomiary wykonywano w warunkach produkcyjnych trzech pomorskich gospodarstw rolnych, z których jedno zajmuje się towarową produkcję zbóż i mleka zaś dwa pozostałe wyłącznie towarową produkcją roślinną, głównie zbóż i rzepaku.

W pierwszym gospodarstwie, które umownie oznaczono jako A (tab.1), wiosną 2011 roku badano emisję amoniaku z mocznika stabilizowanego inhibitorem ureazy NBPT (nazwa handlowa moNolith46) i mocznika bez inhibitora, bezpośrednio po ich zastosowaniu na użytki zielone.

Do celów doświadczalnych na łące trwałej, położonej na madzie średniej pylastej, wyznaczono dwa poletka o powierzchni $100 \mathrm{~m}^{2}$, na których pod drugi odrost traw, zastosowano nawożenie azotem w dawce $60 \mathrm{~kg} \mathrm{~N} \cdot \mathrm{ha}^{-1} \mathrm{w}$ postaci monolithu46 - pierwsze poletko oraz mocznika - drugie poletko. Masę ulatniającego się amoniaku z zastosowanych nawozów kontrolowano przez okres 96 godzin tj. do chwili gdy jego emisja była już poniżej czułości zastosowanej techniki pomiarowej. Doświadczalne pomiary emisji amoniaku z roztworów saletrzano-mocznikowych (RSM) przeprowadzono na przełomie lutego i marca 2012 roku w gospodarstwie oznaczonym umownie jako B.

Badania przeprowadzono na plantacji rzepaku ozimego, na której znajdowały się rośliny częściowo uszkodzone przez mróz (wystąpiła u nich znaczna redukcja rozety liściowej). Korzystając z opryskiwacza polowego (rys.1), przystosowanego do oprysku grubokroplistego, zastosowano nawożenie azotem w dawce $100 \mathrm{~kg} \mathrm{~N} \cdot \mathrm{ha}^{-1}$ w postaci RSM-28.

Wybrany termin aplikacji nawozu był uzasadniony z powodów opisanych wyżej, zaś jego forma w postaci roztworu saletrzano-mocznikowego była praktycznie jedynym możliwym sposobem na szybką i efektywną regenerację uszkodzonych roślin.

W tych konkretnych warunkach produkcyjnych, doświadczenie przeprowadzono na dwóch poletkach doświadczalnych, każde o powierzchni $500 \mathrm{~m}^{2}$, położonych na madzie średniej pylastej.

$\mathrm{Na}$ pierwszym $\mathrm{z}$ nich zastosowano RSM-28 zawierający inhibitor urazy NBPT o stężeniu $0,5 \%$ wag. zaś na drugim RSM-28 bez inhibitora. Pomiary emisji amoniaku na poletkach zakończono po upływie piątej doby od aplikacji nawozów.

Kolejny pomiar emisji amoniaku przeprowadzono w gospodarstwie rolnym C, gdzie w marcu 2012 roku również stosowano RSM-28 do nawożenia plantacji pszenicy ozimej położonej na glebie brunatnej właściwej o składzie granulometrycznym piasku gliniastego.

Dla celów doświadczalnych również tutaj wyznaczono dwa poletka o powierzchni $500 \mathrm{~m}^{2}$ i na każdym $\mathrm{z}$ nich zastosowano nawożenie azotem $\mathrm{w}$ dawce 
$60 \mathrm{~kg} \mathrm{~N} \cdot \mathrm{ha}^{-1}$ w postaci RSM - 28. Na pierwszym poletku zastosowano nawóz $\mathrm{z}$ dodatkiem inhibitora urazy o stężeniu jw. zaś na drugim nawóz bez inhibitora.

Tabela 1. Ogólna charakterystyka warunków glebowo-klimatycznych podczas wykonywania doświadczeń polowych

Table 1. Characterization of soil and climatic conditions during field experiments

\begin{tabular}{|c|c|c|c|c|}
\hline $\begin{array}{l}\text { Kod } \\
\text { gosp. }\end{array}$ & $\begin{array}{l}\text { Rodzaj nawozu } \\
\text { i miejsce jego zasto- } \\
\text { sowania }\end{array}$ & $\begin{array}{l}\text { Rodzaj } \\
\text { gleby }\end{array}$ & $\begin{array}{c}\text { pH } \\
\text { gleby }\end{array}$ & $\begin{array}{c}\begin{array}{c}\text { Pojemność } \\
\text { sorpcyjna gleby } \\
\text { wobec kationów }\end{array} \\
\mathrm{cmol}(+) \cdot \mathrm{kg}^{-1}\end{array}$ \\
\hline \multirow{2}{*}{ A } & $\begin{array}{c}\text { Mocznik+NBPT } \\
\text { łaka trwała }\end{array}$ & $\begin{array}{l}\text { Mada } \\
\text { średnia }\end{array}$ & 4,73 & 20,8 \\
\hline & $\begin{array}{c}\text { Mocznik } \\
\text { tąka trwała }\end{array}$ & $\begin{array}{l}\text { Mada } \\
\text { średnia }\end{array}$ & 5,01 & 20,5 \\
\hline \multirow{2}{*}{ B } & $\begin{array}{l}\text { RSM28+NBPT } \\
\text { rzepak ozimy }\end{array}$ & $\begin{array}{c}\text { Mada } \\
\text { średnia pylasta }\end{array}$ & 7,26 & 30,2 \\
\hline & $\begin{array}{c}\text { RSM28 } \\
\text { rzepak ozimy }\end{array}$ & Mada średnia pylasta & 7,16 & 32,2 \\
\hline \multirow{2}{*}{$\mathrm{C}$} & $\begin{array}{l}\text { RSM28+NBPT } \\
\text { pszenica ozima }\end{array}$ & Brunatna właściwa & 6,33 & 28,5 \\
\hline & $\begin{array}{c}\text { RSM28 } \\
\text { pszenica ozima }\end{array}$ & Brunatna właściwa & 6,30 & 27,0 \\
\hline
\end{tabular}

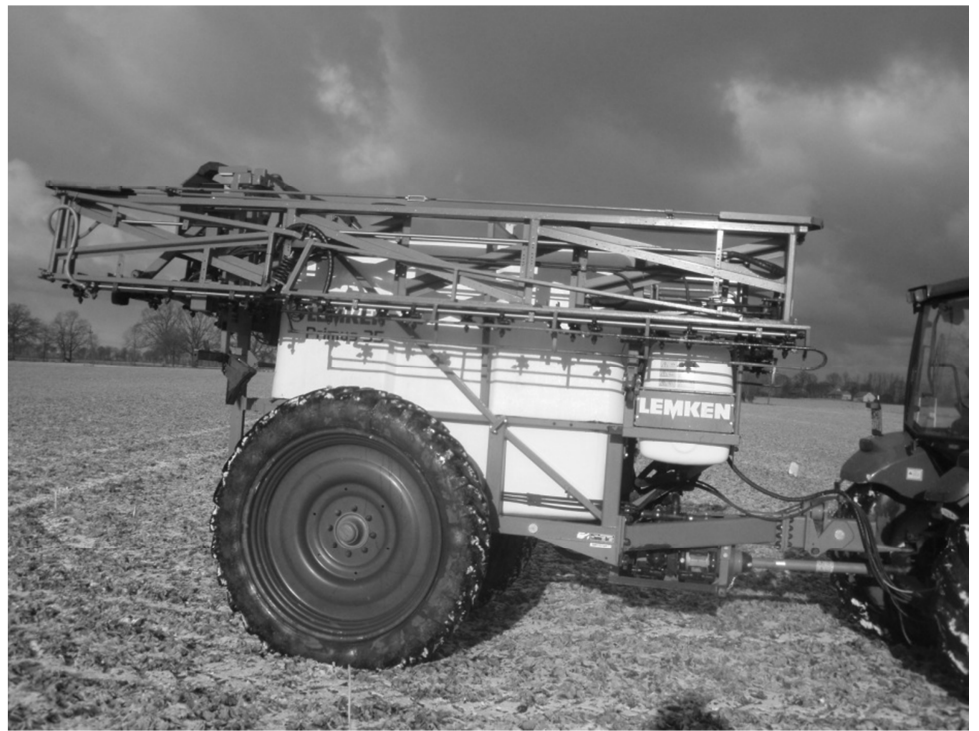

Rys. 1. Opryskiwacz polowy wykorzystywany do aplikacji roztworów RSM

Fig. 1. Field sprayer used for apication UAN solution 
Tabela 1. Ogólna charakterystyka warunków glebowo-klimatycznych podczas wykonywania doświadczeń polowych, cd.

Table 1. Characterization of soil and climatic conditions during field experiments, cd.

\begin{tabular}{|c|c|c|c|c|}
\hline \multirow[t]{2}{*}{$\begin{array}{l}\text { Kod } \\
\text { gosp. }\end{array}$} & $\begin{array}{c}\text { Dawka } \\
\text { azotu }\end{array}$ & $\begin{array}{c}\text { Maksymalna } \\
\text { temperatura } \\
\text { powietrza }\end{array}$ & $\begin{array}{c}\text { Prędkośćc } \\
\text { wiatru }\end{array}$ & \multirow[t]{2}{*}{ Uwagi } \\
\hline & kg N$\cdot h^{-1}$ & ${ }^{\circ} \mathbf{C}$ & $\mathbf{m} / \mathbf{s}$ & \\
\hline \multirow{2}{*}{ A } & 60 & $25-32$ & $0,3-4,0$ & \multirow{2}{*}{$\begin{array}{c}\text { Niewielki deszcz } \\
\text { w } 4 \text { dobie }\end{array}$} \\
\hline & 60 & $25-31$ & $0,3-4,0$ & \\
\hline \multirow{2}{*}{ B } & 100 & $0-9,5$ & $0,3-2,0$ & \multirow{2}{*}{$\begin{array}{c}\text { Niewielki deszcz } \\
\text { w } 4 \text { dobie }\end{array}$} \\
\hline & 100 & $0-10$ & $0,3-2,0$ & \\
\hline \multirow{2}{*}{$\mathrm{C}$} & 60 & $4-15$ & $2,0-6,0$ & \multirow{2}{*}{$\begin{array}{c}\text { Niewielki deszcz } \\
\text { w } 3 \text { dobie }\end{array}$} \\
\hline & 60 & $4-15$ & $2,0-6,0$ & \\
\hline
\end{tabular}

Pomiary amoniaku oraz niezbędne obserwacje agrotechniczne zakończono $\mathrm{z}$ upływem piątej doby od aplikacji nawozów.

\subsection{Ilościowe pomiary emisji amoniaku}

Pomiary prowadzono w oparciu o 24-godzinny czas ekspozycji 32 rurkowych dozymetrów pasywnych [8], wewnątrz powleczonych cienką warstwą sorbenta - kwasu szczawiowego, które umieszczano na masztach pomiarowych (rys.2) ustawianych symetrycznie wzdłuż czterech boków poletka doświadczalnego.

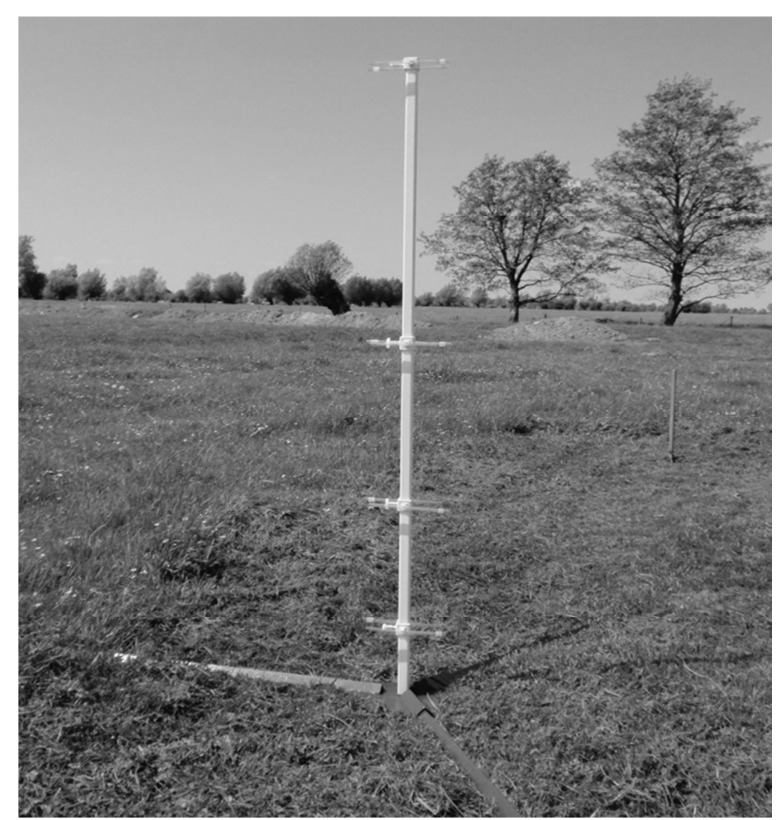

Rys.2. Maszt przygotowany do pomiarów emisji amoniaku

Fig. 2. The measuring mast ready for collecting data 
We wszystkich gospodarstwach emisję amoniaku z badanych nawozów mineralnych szacowano techniką mikrometeorologicznej dozymetrii pasywnej $[2,3]$.

Gęstość pionowego strumienia amoniaku mierzono w czterech różnych przedziałach wysokości, licząc od powierzchni źródła emisji, jednakże do wysokości nie większej niż 2,0 - 2,5 m.

Zebrany amoniak w postaci szczawianu amonu ekstrahowano $\mathrm{z}$ dozymetrów $5 \mathrm{~cm}^{3}$ wody dejonizowanej i oznaczano kolorymetrycznie z zastosowaniem autoanalizera przepływowego marki FIA Compact.

\section{Wyniki i ich omówienie}

Uzyskane wyniki polowych pomiarów emisji (tab. 2) wskazują, że gazowe straty tej formy azotu $\mathrm{z}$ syntetycznych nawozów azotowych stosowanych w mineralnym żywieniu roślin uprawnych mogą być bardzo zróżnicowane i zależą od wielu czynników. W warunkach przeprowadzonych doświadczeń polowych oraz $\mathrm{w}$ zależności od rodzaju i dawki zastosowanych nawozów, kształtowały się one w szerokim zakresie od 1,18 do $9,60 \mathrm{~kg} \mathrm{~N} \cdot \mathrm{ha}^{-1}$. W gospodarstwie A gdzie na łąkę trwałą, pod drugi odrost traw zastosowano azot w dawce $60 \mathrm{~kg} \mathrm{~N} \cdot \mathrm{ha}^{-1} \mathrm{w}$ postaci mocznika ale w dwóch wariantach tj. w postaci mocznika stabilizowanego dodatkiem inhibitora NBPT i mocznika bez stabilizatora, emisja amoniaku po upływie czwartej doby wynosiła odpowiednio: 2,60 i 9,60 kg N·ha ${ }^{-1}$. Prawdopodobnie tak duże jej zróżnicowanie spowodowane było dodatkiem do mocznika inhibitora NBPT, który w okresie kilku pierwszych dni od aplikacji nawozu skutecznie hamował jego enzymatyczna hydrolizę do amoniaku [9]. Należy dodać, że doświadczenie polowe w gospodarstwie A prowadzono na poletku położonym na glebie kwaśnej o dobrze rozbudowanym kompleksie sorpcyjnym gleby co nie sprzyjało raczej nadmiernej emisji amoniaku (tab. 1). $\mathrm{Z}$ drugiej jednak strony panujące ekstremalne warunki klimatyczne a zwłaszcza temperatura powietrza, okresowo przekraczające $32{ }^{\circ} \mathrm{C}$ (tab.1), mogła dodatkowo zwiększać ulatnianie się amoniaku. Sommer i wsp. [10] twierdzą, że realny wpływ na wielkość emisji amoniaku z nawozów mogą mieć temperatura i szybkość wiatru, zwłaszcza przy „powierzchniowym” sposobie nawożenia. Również wg cytowanych autorów specyficzny „mikroklimat” użytku zielonego a zwłaszcza duża ,szorstkość” jego powierzchni oraz ograniczony przez roślinność kontakt nawozu z glebą powodują, że proces ulatniania się amoniaku może być dynamiczny. Zatem stosowanie inhibitora ureazy NBPT w przypadku nawożenia tego rodzaju roślin mocznikiem wydaje się być uzasadnione. Doświadczalnie wyznaczona efektywność inhibitora w redukcji strat amoniaku w tym przypadku wynosiła $73 \% \mathrm{w}$ stosunku do mocznika stosowanego bez inhibitora (tab.3). W doświadczeniach polowych przeprowadzonym na plantacjach rzepaku ozimego i pszenicy, nawożonych roztworem RSM 28, stwierdzono, że wzbogacenie nawozu o inhibitor urazy NBPT powoduje wy- 
raźne obniżenie emisji amoniaku. Na plantacji rzepaku ozimego w gospodarstwie B (doświadczenie przeprowadzono w okresie przedwegetacyjnym) zastosowanie dodatku inhibitora do RSM-u skutkowało redukcją gazowych strat azotu o ponad $50 \% \mathrm{w}$ stosunku do strat tego składnika w podobnych warunkach, ale w wariancie bez inhibitora. Biorąc pod uwagę panujące warunki meteorologiczne podczas doświadczenia, w tym stosunkowo niską temperaturę, efektywność procesów inhibicji ureazy należy uznać za bardzo wysoką. W drugim doświadczeniu przeprowadzonym $\mathrm{w}$ gospodarstwie $\mathrm{C} \mathrm{z}$ pszenicą ozimą, dodanie do roztworu RSM28 inhibitora NBPT w ponad $80 \%$ zmniejszyło straty azotu w postaci amoniaku w porównaniu do strat tego składnika jakie stwierdzono w wariancie doświadczenia bez inhibitora. $\mathrm{W}$ obu przypadkach obniżenie strat amoniaku winno zdecydowanie wpłynąc na zwiększenie masy plonu, poprawę jego jakości, a ostatecznie na ekonomiczną i ekologiczną efektywność prowadzonej produkcji roślinnej.

Tabela 2. Emisja amoniaku z nawozów azotowych zastosowanych na poletkach doświadczalnych

Table 2. Ammonia emissions from nitrogen fertilizers applied to experimental plots

\begin{tabular}{|c|c|c|c|c|c|c|c|c|c|}
\hline \multirow{3}{*}{\multicolumn{2}{|c|}{$\begin{array}{l}\text { Kod gospodarstwa } \\
\text { rodzaj nawozu }\end{array}$}} & \multirow{4}{*}{$\begin{array}{c}\begin{array}{c}\text { Dawka } \\
\text { azotu }\end{array} \\
\mathrm{kg} \mathrm{N} \cdot \mathrm{ha}^{-1} \\
60\end{array}$} & \multicolumn{6}{|c|}{$\begin{array}{c}\text { Emisja amoniaku w kolejnych dobach } \\
\text { po aplikacji nawozów }\end{array}$} & \multirow{4}{*}{ 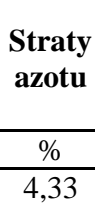 } \\
\hline & & & \multicolumn{6}{|c|}{$\mathrm{kg} \mathrm{N} \cdot \mathrm{ha}^{-1}$} & \\
\hline & & & 1 & 2 & 3 & 4 & 5 & Razem & \\
\hline \multirow{2}{*}{ A } & Mocznik+NBPT & & 0,38 & 1,87 & 0,30 & 0,00 & - & 2,60 & \\
\hline & Mocznik & 60 & 5,10 & 4,40 & 0,14 & 0,00 & - & 9,60 & 16,0 \\
\hline \multirow{2}{*}{ B } & RSM28+NBPT & 100 & 2,72 & 0,64 & 0,36 & 0,01 & 0,00 & 3,73 & 3,73 \\
\hline & RSM28 & 100 & 3,34 & 2,99 & 1,17 & 0,19 & 0,41 & 8,10 & 8,10 \\
\hline \multirow{2}{*}{ C } & RSM28+NBPT & 60 & 0,00 & 0,09 & 0,63 & 0,46 & 0,00 & 1,18 & 2,00 \\
\hline & RSM28 & 60 & 1,14 & 4,66 & 0,69 & 1,54 & 0,58 & 8,61 & 14,4 \\
\hline
\end{tabular}

Tabela 3. Doświadczalnie wyznaczona efektywność NBPT w redukcji emisji amoniaku

Table 3. The effectivenes of NBPT in reducing ammonia emission

\begin{tabular}{|c|c|c|}
\hline Kod gospodarstwa & Porównywane nawozy & \% redukcji \\
\hline A & Mocznik+NBPT & 73 \\
\hline B & RSM28+NBPT & 51 \\
\hline C & RSM28+NBPT & 80 \\
\hline
\end{tabular}

\section{Podsumowanie}

Emisja amoniaku z rolnictwa jako głównego antropogenicznego źródła tego gazu, jest i zapewne długo jeszcze będzie problemem, który zarówno z powodów ekonomicznych jak i stale narastających globalnych zagrożeń ekologicznych, wymagać będzie podejmowania innowacyjnych działań o charakterze naukowym i praktycznym, których podstawowym celem będzie jej ograniczanie. 
Czołowa pozycja mocznika i roztworów saletrzano- mocznikowych RSM w światowym i krajowym rynku nawozów azotowych głównie z powodów technologicznych i agronomicznych jest nie kwestionowana. Jednak główna ich wada to podatność na straty gazowe w postaci amoniaku, które w świetle wcześniejszych badań wykonanych głównie [5,6] w Instytucie Technologiczno Przyrodniczym w Falentach, w warunkach nawożenia użytków zielonych, przekraczają 30\% czystego składnika.

Biorąc pod uwagę podstawowe zasady Dobrych Praktyk Rolniczych jak również względy ekonomiczne, do nawożenia użytków zielonych mocznik w postaci stałej bez inhibitora ureazy nie powinien być zalecany.

Również stosowane coraz częściej w mineralnym żywieniu roślin uprawnych, płynne nawozy azotowe, w tym roztwory saletrzano-mocznikowe RSM powinny być wzbogacane o tego rodzaju dodatki ograniczające emisję amoniaku do atmosfery.

Obecnie wiadomo, że dzięki zastosowaniu inhibitora urazy np. w monolith46 jego podatność na hydrolizę do amoniaku, przynajmniej przez okres czterech do pięciu dniu od powierzchniowego zastosowania nawozu, może być wydanie ograniczona.

Zatem wzrost efektywność tej formy azotu w mineralnym żywieniu roślin jest wysoce prawdopodobny zaś zysk ekologiczny, co wyraźnie wynika z uzyskanych wyników badań w gospodarstwach, niepodważalny.

\section{Literatura}

[1] Erisman J, Bleeker A, Hansen A, Vermeulen A.: Agricultural air quality in Europe and the future perspectives, Atmospheric Environment, vol. 42, 2008, pp. 32093217.

[2] Ferm M., Marcinkowski T., Kieronczyk M., Pietrzak S.: Measurements of ammonia emissions from manure storing and spreading stages in Polish commercial farms, Atmospheric Environment, vol. 36, 2005, pp. 7106-7113.

[3] Gericke D, Pacholski A, Kage H.: Measurement of ammonia emissions in multiplot field experiments, Biosystems Engineering, vol. 108, 2011, pp. 164-173.

[4] Kalda G., Łopuszyńska P.: Analiza zagrożeń środowiska Podkarpacia, Czasopismo Inżynierii Lądowej, Środowiska i Architektury, z. 61, 2014, s. 101-117.

[5] Marcinkowski T.: Emisja gazowych związków azotu z rolnictwa, WodaŚrodowisko-Obszary Wiejskie, t. 10, z. 3, 2009, s. 175-189.

[6] Marcinkowski T., Kierończyk M., Martyna A.: Szacowanie emisji amoniaku $\mathrm{z}$ mineralnych nawozów azotowych w świetle wyników doświadczenia polowego, Rozprawy Naukowe i Zawodowe PWSZ w Elblągu, z. 15, 2012, s. 33-40.

[7] Rozporządzenie Komisji (UE) nr 1257/2014 z dnia 24 listopada 2014 r., zmieniające rozporządzenie (WE) nr 2003/2003 Parlamentu Europejskiego i Rady w sprawie nawozów w celu dostosowania załączników I i IV.

[8] Namieśnik J, Jamrugiewicz Z.: Fizykochemiczne metody kontroli zanieczyszczenia środowiska, Wydawnictwa Naukowo-Techniczne, Warszawa 1998, ss. 462. 
[9] Sanz-Cobena A., Misselbrook T., Arce A., Mingot J., Diez J., Vallejo A.: An inhibitor of urease activity reduces ammonia emissions from soil treated with urea under Mediterranean conditions, Agriculture Ecosystems \& Environment, vol. 126, 2008, pp. 243-249.

[10] Sommer SG, Hutchings NJ.: Ammonia emission from field applied manure and its reduction-invited paper, vol. 15, 2001, pp. 1-15.

\title{
EFFECTIVENESS OF UREASE INHIBITOR NBPT IN MITIGATION AMMONIA EMISSION FROM UREA AND UREA AMMONIUM NITRATE SOLUTIONS (UAN) APPLIED IN MINERAL FERTILIZATION OF PLANTS
}

\begin{abstract}
S u m m a r y
The assessment of effectiveness urea inhibitor (NBPT) in mitigation ammonia emission from urea and urea ammonium nitrate solutions (UAN) - fertilizers widely applied in mineral fertilization of plants was objective of this experimental research. Experimental study was conducted in 2011 and 2012 year in several farms located in Pomerania region. Conditions of field experiment, placed in alluvial soils, stated that losses of nitrogen after nitrogen fertilization $60 \mathrm{~kg} \mathrm{~N} \cdot \mathrm{ha}^{-1}$, for second cuts of grass, after 4 to 5 days, in urea experiment was about $16,0 \%$ and with stabilized urea (with NBPT) $4,3 \%$ to the initial amount of nitrogen. Based on the experimental data using of urea inhibitor like NBPT may cause reduction of ammonia emission by $73 \%$. Experiments in field conditions carried out at winter rape and wheat plant fertilized using urea ammonium nitrate solution (UAN-28) shows that enrichment UAN with inhibitor of urease (NBPT) decrease ammonia emission. Winter rape plant fertilized by $100 \mathrm{~kg} \mathrm{~N} \cdot \mathrm{ha}^{-1}$ with addition of inhibitor to UAN solution resulted in reduction of nitrogen losses up to $50 \%$ than applied without inhibitors. Second experiment carried out at winter wheat plant fertilized by $60 \mathrm{~kg} \mathrm{~N} \cdot \mathrm{ha}^{-1}$ with addition to UAN solution inhibitor (NBPT) decreased ammonia losses to $80 \%$ in comparison to experiment of fertilization without using inhibitor. In all researches decreasing of ammonia emission caused improvement of yields. This results underline that using inhibitors improve economical and environmental efficiency at plant production level.
\end{abstract}

Keywords: urea, urease, NBPT, fertilization, ammonia emission

Przestano do redakcji: $30.05 .2015 \mathrm{r}$.

Przyjęto do druku: 30.10.2015 r.

DOI: $10.7862 / \mathrm{rb} .2015 .112$ 